To cite this article: Clement C. Ukangwa, Evans C. Otuza \& Maria Ehioghae (2020) Influence of Information Sharing on Job Satisfaction of Librarians in Private Universities in South-East and SouthWest, Nigeria. Information Impact: Journal of Information and Knowledge Management, 11:4, 129-137, DOI: https://dx.doi.org/10.4314/iijikm.v11i4.12

To link to this article: https://dx.doi.org/10.4314/iijikm.v11i4.12

\title{
Trends in Inaugural and Public Lecture Presentations at the Federal University of Technology, Owerri (FUTO), 1986-2019
}

\author{
${ }^{1}$ Chinwe V. Anunobi \\ ${ }^{2}$ Colette O. Onyebinama \\ ${ }^{1}$ Festus Aghagbo Nwako Library, Nnamdi Azikiwe University, Awka, Nigeria \\ ${ }^{2}$ Federal University of Technology Library, Owerri, Nigeria
}

\section{Abstract}

This study is designed to determine the trend of inaugural and public lecture presentations at the Federal University of Technology, Owerri (FUTO), from 1986 - 2019. A total of thirty-five hard copies of the inaugural and thirty-three public lectures were retrieved from the University Library for the research. The frequency of presentation, gender of the lecturers, discipline/programme, subject matter and trend of presentation of the lectures were analyzed using descriptive statistics including frequency tables, percentages, charts and graphs. Findings revealed that only a few lecturers have presented their inaugural lectures compared to the number of Professors in the University. More males had presented lectures, when compared to females. Sciences, Engineering, Agriculture and Management had low presentation. The subjects of the public lecture revolved around and demonstrated the societal challenges and issues at the time of the presentations. Recommendations were made primarily to ensure motivation and policy position on inaugural and public lectures presentation.

Keywords Inaugural lectures, Public lectures, Research, Universities

CONTACT Chinwe V. Anunobi, and Colette O. Onyebinama okcoleto@yahoo.com Nnamdi Azikiwe University Library,Awka, Nigeria and Federal University of Technology Library, Owerri, Nigeria. 


\section{Introduction}

Universities all over the world are considered the ivory tower where research and invention are carried out and delivered for societal development. It is a place where knowledge (tacit and implicit) is made and presented for continuous learning and development. Scholars in the university are expected to carry out state-of the-art research which are consequently documented and patented in some cases. Scholarly growth through research often earns faculty members in the university promotion to the position of professors. The term "Professor" means those at the pinnacle of the academic staff hierarchy (Full Professor) (Evans, 2017).

Professors in the University system are provided opportunity to showcase their research output in highly celebrated gathering termed Inaugural Lecture. During the lecture, Professors share their achievements and contributions to the societal development with colleagues, families, friends and members of the university community. Additionally, scholars in the University system can also present lectures on topical issues or areas of interest for the benefit of the University community and the society at large. These lectures are usually celebrated and serves as a "town and gown" responsibility of the university. It is also an indication that the university is leaving up to one of its major responsibility which is carrying out research for developmental initiative and for the education of the wider society.

The Federal University of Technology, Owerri (FUTO), the premier University of Technology in Nigeria, which was established in 1980 has its own share of inaugural and public lectures activities. From its initial 3 Schools - SAAT, SOSC and SEET with 50 Professors, it has grown to 8 Schools with 175 Professors. It is expected that the increasing number of schools and professors will translate to increasing number of inaugural and public lectures in diverse disciplines and research domains. Considering that the university is among the ranking institutions in Nigeria with strong base in technology, it is therefore imperative to determine the trend in the University's inaugural and public lecture activities viz-a-viz frequency of presentation, gender, disciplines/programme, subject matter and trend of presentations with a view to making projection on future town and gown university's responsibility, hence this study.

\section{Purpose of the Study}

The central purpose of the study was to determine the trend in inaugural and public lectures presentation in FUTO. The specific objectives are to:

- Determine the frequency of inaugural and public lecture presentations at FUTO

- Find out the distribution of inaugural and public lecture presentations at FUTO based on gender

- Find out the distribution of inaugural lecture presentations at FUTO based on discipline/programme of the presenter

- Find out the distribution of public lecture presentations at FUTO based on subject

- Determine the trend of inaugural and public lecture presentations at FUTO from 1986-2019

\section{Research Questions}

The following research questions guided the study:

- What is the frequency of inaugural and public lecture presentations at FUTO?

- What is the distribution of inaugural and public lecture presentations at FUTO based on gender

- What is the distribution of inaugural lecture presentations at FUTO based on discipline/programme of the presenter?

- What is the distribution of public lecture presentations at FUTO based on subject?

- What is the trend of inaugural and public lecture presentations at FUTO from 1986-2019? 


\section{Literature review}

The term "inaugural lecture" has been variously defined by several authors. Omolehin (2018) described inaugural lecture as one of the important functions of a university system which is a basis for which a lecturer is promoted to full chair. The lecturer is expected to showcase his area of research with a view to collaborating with other researchers to solve or to address some contemporary problems facing the society. Similarly, Leather (2013), opined that inaugural lecture is the first lecture given by a newly appointed professor. According to the author, inaugural lectures are a long-established feature of university life and are highlighted as being events of some consequence to the university or department of which the 'newly' appointed professor has become a part. In giving an inaugural lecture, the new professor can celebrate an important personal milestone with family, friends and colleagues, old and new. On the other hand, Ekpo (2015) described inaugural lectures as debts that professors owe the university system and as one of the legacies of the global university system. The inaugural lecture is thus a platform for newly appointed professors to share their brilliant discoveries, innovative ideas and deep insights with the public and the larger academic community. Professionals and academics gain a unique opportunity to engage across knowledge boundaries for the benefit of humankind. Inaugural lectures are attended by faculty members from one's or other departments, researchers, assistants, civil servants, students, journalists, administrative and technical staff, relatives and friends etc.

Soneye (2017) posited that inaugural lectures are delivered for two reasons. First, it is an occasion for a newly appointed Professor to mark his career achievement by presenting his contributions to knowledge and development in his chosen field locally and internationally. The lecture also provides an opportunity for a Professor to inform his audience, colleagues, the campus community and the public of his/her work to date, including current research and future. Oliver (as cited in Farinu, 2015), is of the view that the purpose of an inaugural lecture is to give the new appointed incumbent an opportunity to state in public what he professes to know of his subject. Nwala (as cited in UCT Inaugural Lecture Series, 2013) gave reasons why a professor should give an inaugural lecture as respect for academic tradition; for the sake of intellectual history (unless the younger generation understands the point their predecessors have reached, they will not know the significance of their own contribution); for the sake of one's mentor, students and associates; and in order to engage in public discourse of one's work. However, Ayeni (2012) summarized the importance of inaugural lecture based on an excerpt from Imperial College London as: "The lecturer is expected to present an overview of his/her research and update colleagues on the current and future plans and introduce the research to a wider audience. Furthermore, it also provides opportunity for the Department to engage with broader audiences inside and outside the institution to establish new collaborations, strengthen the existing relationship and catch up with Alumni. The University can also use inaugural lecture to engage with audiences with a broader interest research, including fund raiser and decision makers from government, academic and industry.

However, public lectures are simply described as lectures for the public. This means that the lecturer is not speaking before his colleagues, but he/she is speaking to an audience that is not knowledgeable but is eager to learn. In other words, the lecturer must explain in simple words the basis of the subject of the lecture. Public lectures are not given on a specific research rather it can be given on a topical issue that is in the new. Public lectures are organized in educational institutions and leisure centers to promote academic knowledge.

Consequently, Ivanov and Ivanova (2018) are of the view that public lectures aim to transfer knowledge, to learn to operate it, help to broaden horizons. The most important goals of public lectures are to unleash listener's creative potential, to develop one's value orientations and moral qualities in professional, social activities and in personal life. It also helps one to engage with the local community, alumni or students, share knowledge, inspire donors or attract future students. It is an opportunity for universities to engage with government, business and the public to inform and educate the community through leading open discussion of 
issues that confront our nation, our region and the world. Public lectures are given because it provides a valuable opportunity for citizens to learn about new research. Researchers who are new to public engagement are often more comfortable engaging with the public in this way. Public lecture is more about giving, or disseminating information, but there can be time for feedback and debate if needed.

\section{Methodology}

All inaugural and public lectures presented in FUTO from 1986 when the first lecture was presented to 2019 were retrieved from the University Library. There was a total of thirty-five inaugural and thirty-three public lectures. The frequency, gender of the lecturers, discipline/programme, subject and trend of presentations were analyzed using descriptive statistics such as frequency tables, percentages, charts and graphs.

\section{Results}

The results were presented as answers to the five research questions posed to guide the research.

Research Question 1

What is the frequency of inaugural and public lecture presentations at FUTO

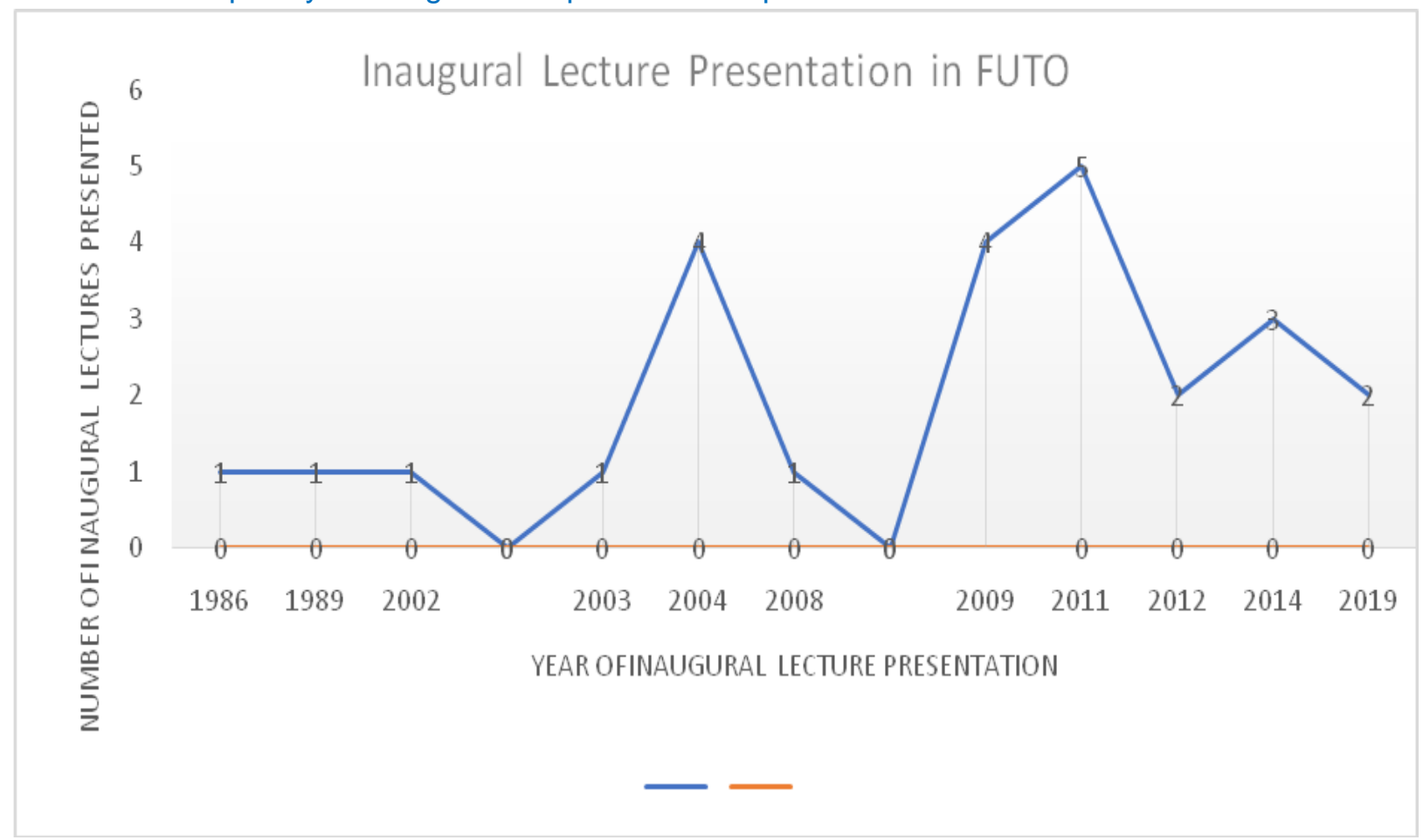

Fig 1: Frequency of Inaugural Lecture Presentation in FUTO

The Federal University of Technology, Owerri (FUTO) recorded a total of sixty-eight (68) lectures from 1985 to 2019 comprising of 35 inaugural and 33 public lectures. This shows that there were more inaugural lectures (51.4\%) than public lecturers $(48.5 \%)$ delivered during the period under consideration. The frequency of presentation of the inaugural and public lectures is presented in Figure 1 above \& figure 2 below. 


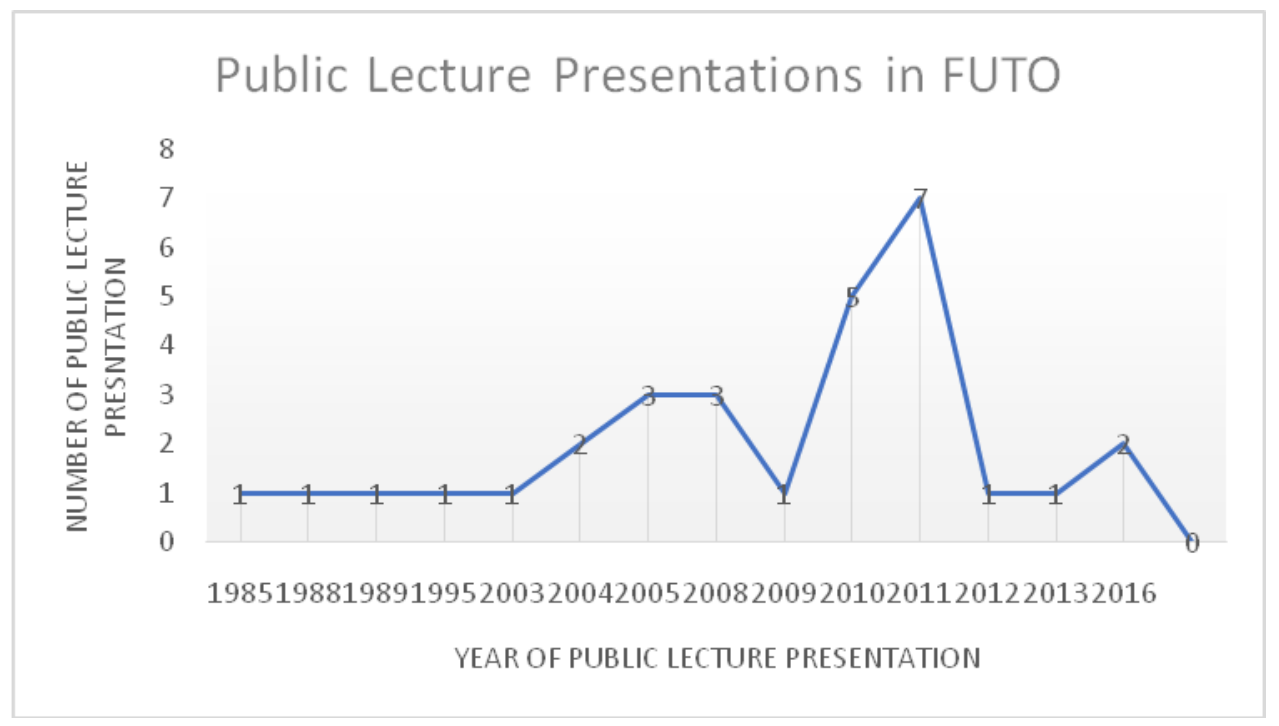

Fig 2: Frequency of Public Lecture Presentations in FUTO.

For the 35 inaugural lectures recorded during the period, the highest number of $5(16.7 \%)$ was presented in the year 2011. This was followed by the years 2004 and 2009 which recorded 4 (13.3\%) inaugural lectures each. Unfortunately, out of the 34 years under study, there were no inaugural lectures in twelve (34.3\%)years including, 1987, 1988, 2000 ,2001, 2005, 2006, 2007, 2010, 2013, 2015, 2017, and 2018 etc. as shown in Figure 1 above. The absence of lack of inaugural lecture during these years is an issue for concern as the university continued to promote more academic to professorial rank. It could be a result of indolence, lack of motivation or absence of policy to ensure the needful is done.

Also, of the thirty-three public lectures recorded during the period, the highest number was presented in the year 2011 with 7 (21.2\%) public lectures. This was followed by the year 2010 which recorded 5 (15.15\%) public lectures. Unfortunately, out of the 34 years under study, there were a total of $18(56.25 \%)$ years, including 1986, 1987, 1990 etc. as shown in Figure 2 within which no public lecture was presented. Since the University did not record inaugural and public lectures within some years, it means the institution may not have a policy to determine when and what should be presented.

\section{Research Question 2}

What is the distribution of inaugural and public lecture presentations at FUTO based on gender?

The distribution of the lecturers' gender is shown in Figure 3 below. Out of the 69 lectures delivered during the period under consideration, the female lecturers delivered $5(7.24 \%)$ of the lectures, while the remaining $64(92.75 \%)$ lectures were delivered by their male counterparts. Specifically, only three $3(8.57 \%)$ of the inaugural lectures were presented by the female lecturers contrary to the $32(91.42 \%)$ presented by the male lecturers. This could be attributed to the number of female Professors against the male which stood at twentyfive (25) and one hundred and fifty (150) respectively as at January 2020 (Senate Meeting Proceedings January, 2020). However, as shown in the figure, gender distribution of the thirty-three public lectures shows similar trend where only $2(6.06 \%)$ of the lectures were delivered by female lecturers, while the remaining 31 (93.94\%) were presented by male lecturers. This could mean that the male lecturers were more proactive in lecture 
presentations in view of the fact that public lecture is not restricted to Professors but open to any staff who demonstrates the willingness to do so.

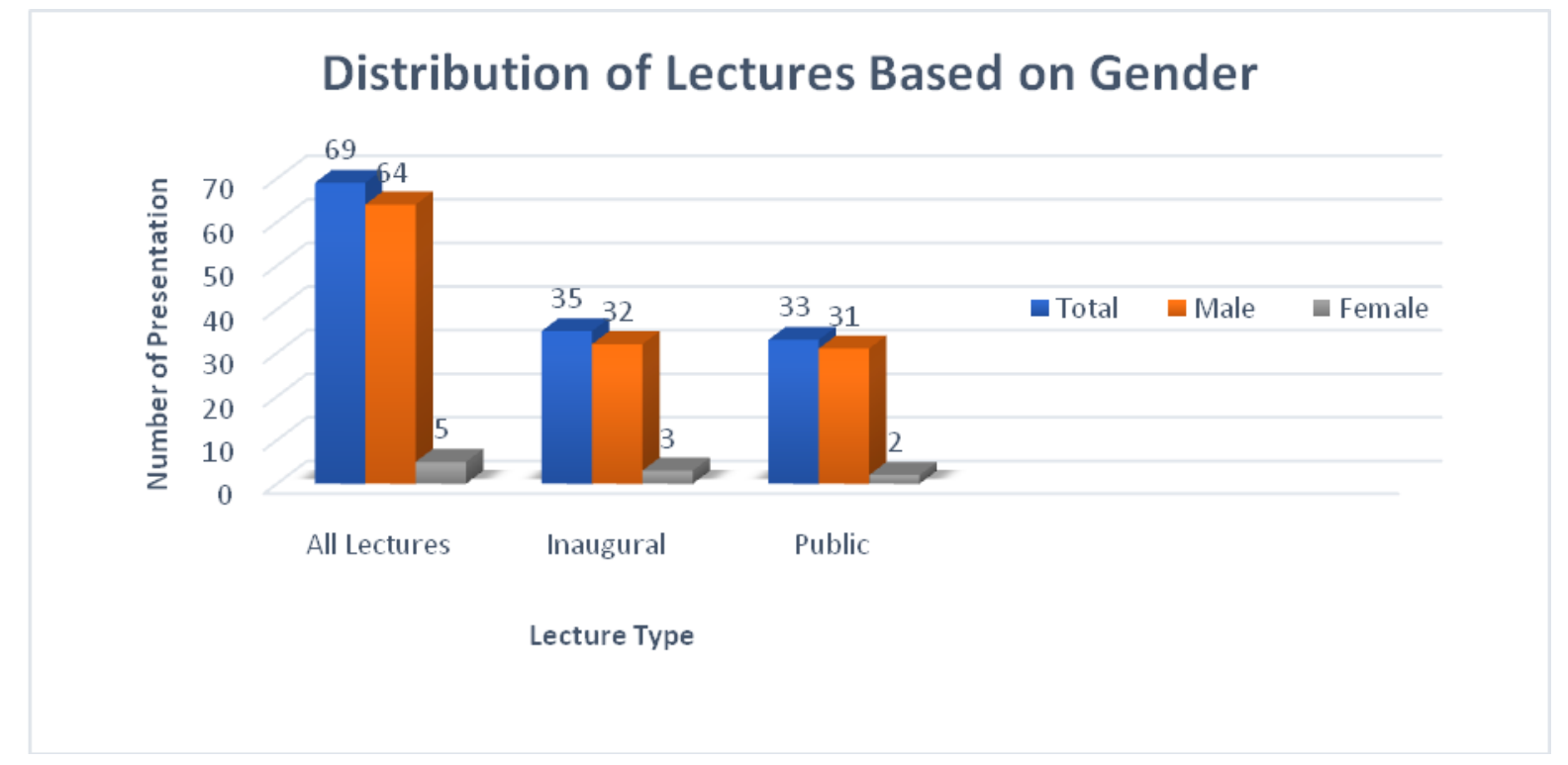

Fig 3: Distribution of Inaugural and Public Lectures Presentation Based on Gender

\section{Research Question 3}

What is the distribution of inaugural lecture presentations at FUTO based on discipline/programme?

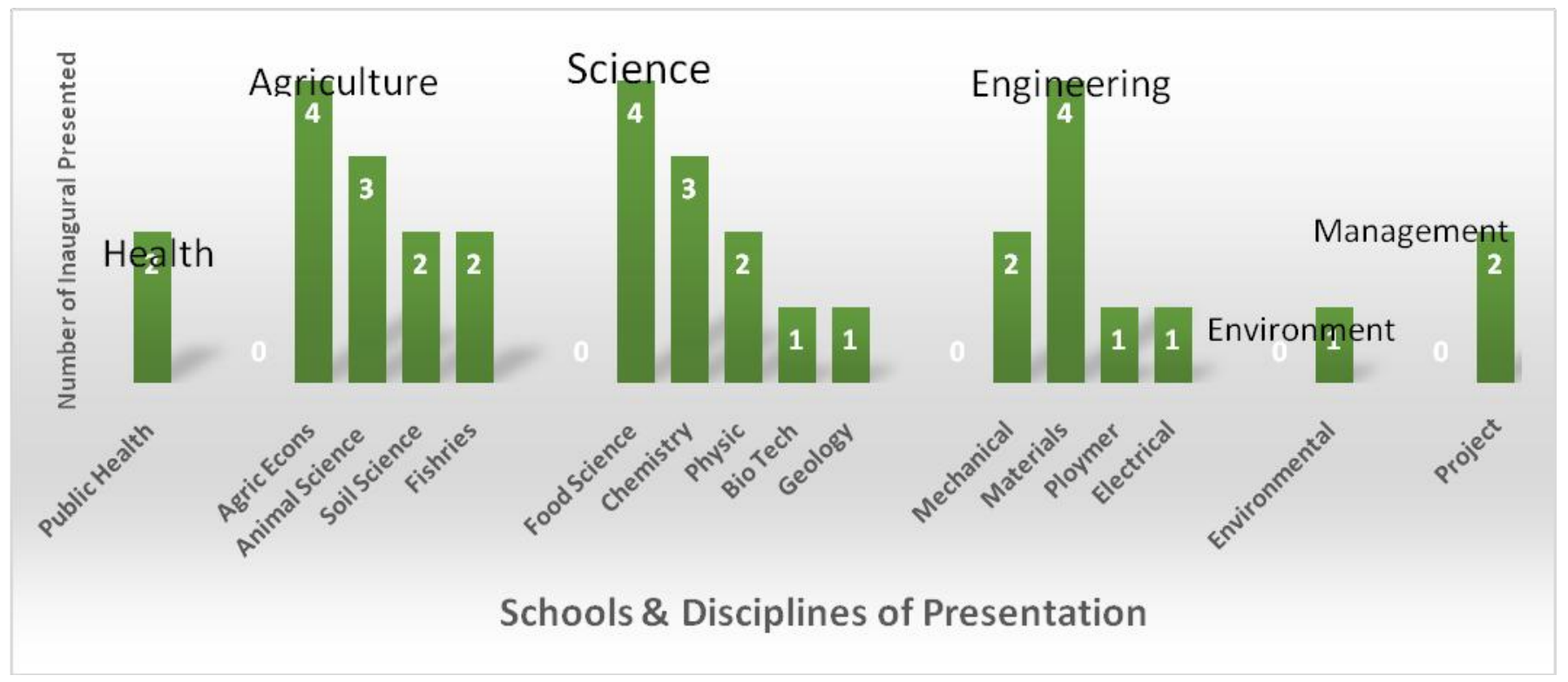

\section{Fig 4: Distribution of Inaugural Lecture Presentations Based on Discipline}

The distribution of the inaugural lecture presentations based on discipline is presented in Figure 4 above. It shows that staff of five schools(faculty) out of eight and sisteen discipline out of forty-seven had presented inaugural lectures in the University respectively. This is an indication of a very poor inaugural 
lectures outing in the University. Furthermore, only two Professors of Public Health had presented inaugural lecture in the School of Health Technology. Though the School of Agriculture ranked high among the represnted Schools with $31.4 \%$ of inaugurallectures, not all the Departments had a shot on the prestigous lecture. In the Sciences, the Professors of Mathematics, Computer Sceince, and Biological Sciences outside Biotechnology are yet to give back to the society the outcome of their research. Schools of Engineering, Environmnetal Sciences and Management are also poorly represented. However, the distribution of the inaugural lectures is not actually encouraging considering the number of Professors in each of the discipline.

\section{Research Question 4:}

What is the distribution of public lecture presentations at FUTO based on subject?

Subjects of the thirty-three public lecturers portray the concerns of the society and the Uuniversity community at the time of delivery. It ranges from Higher Education (27.3\%), Health and Science /Technology(18.2\%), Environmental Safety(15.2\%), Economy (9.1\%) and Corruption, Politics, Gender and Agriculture which represented (3\%) each of the entire public lectures. The high percentage of Higher Education lecture is understood since the university environment will always seek the ways and means of improving University education at all times. The desire to move the country forward riding on the benefits of education and the increasing health and environmnetal challenges of the twenth-century moving forward could lend support to the $18.2 \%$ and $15.2 \%$ of the lectures in those areas.

\section{Research Question 5}

What is the trend of inaugural and public lecture presentations at FUTO from 1986-2019?

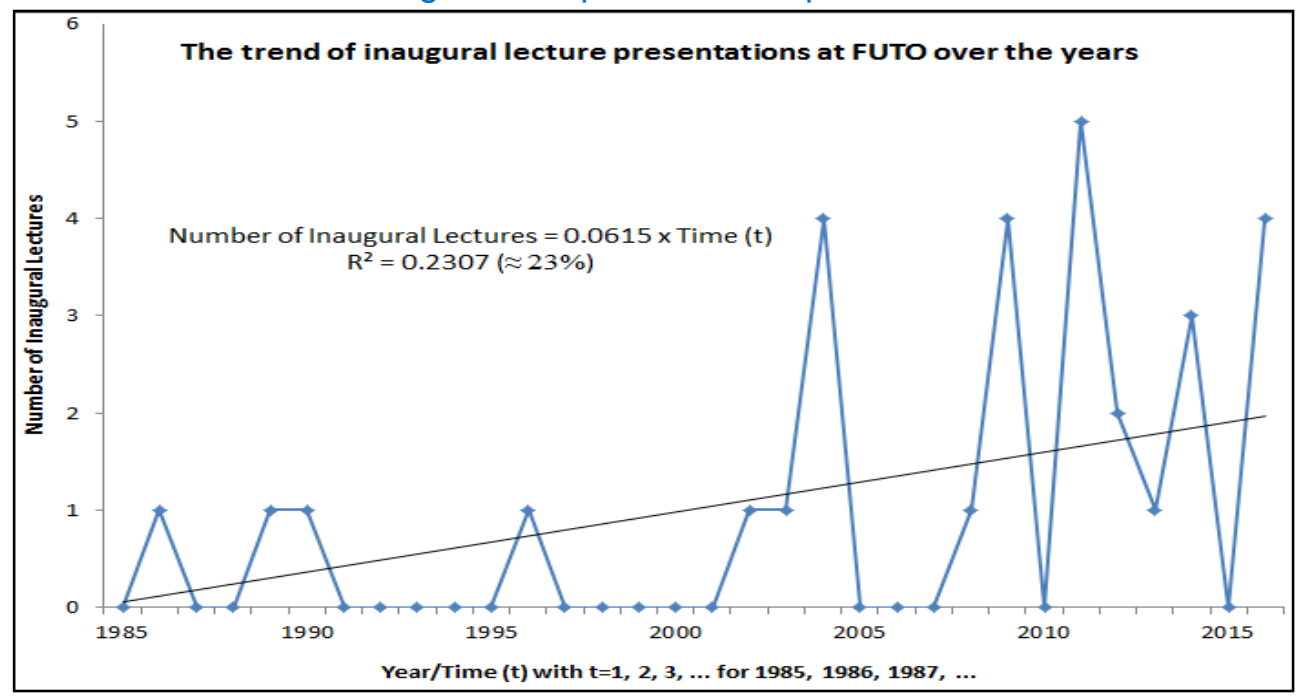

Figure 5: Trends in Inaugural Lecture Presentations in FUTO.

The inaugural lecture series at FUTO have witnessed an upward trend over the years as shown in Figure 5. The upward linear trend associated with the inaugural lectures is obtained as:

Number of Inaugural Lectures $=0.0615 \mathrm{x}$ Time $(\mathrm{t})$

Where Year/Time $(t)=1,2,3, \ldots$ correspond to year 1985, 1986, 1987, etc. The R-square value of 0.2307 or $23 \%$ shows that the linear trend in (1) explains only about $23 \%$ of the variations in the inaugural lecture presentations in FUTO. Hence, the estimated linear trend is not appropriate for prediction purposes since it does not explain up to $75 \%$ of the variations in the inaugural lecture presentations in FUTO over the years. 


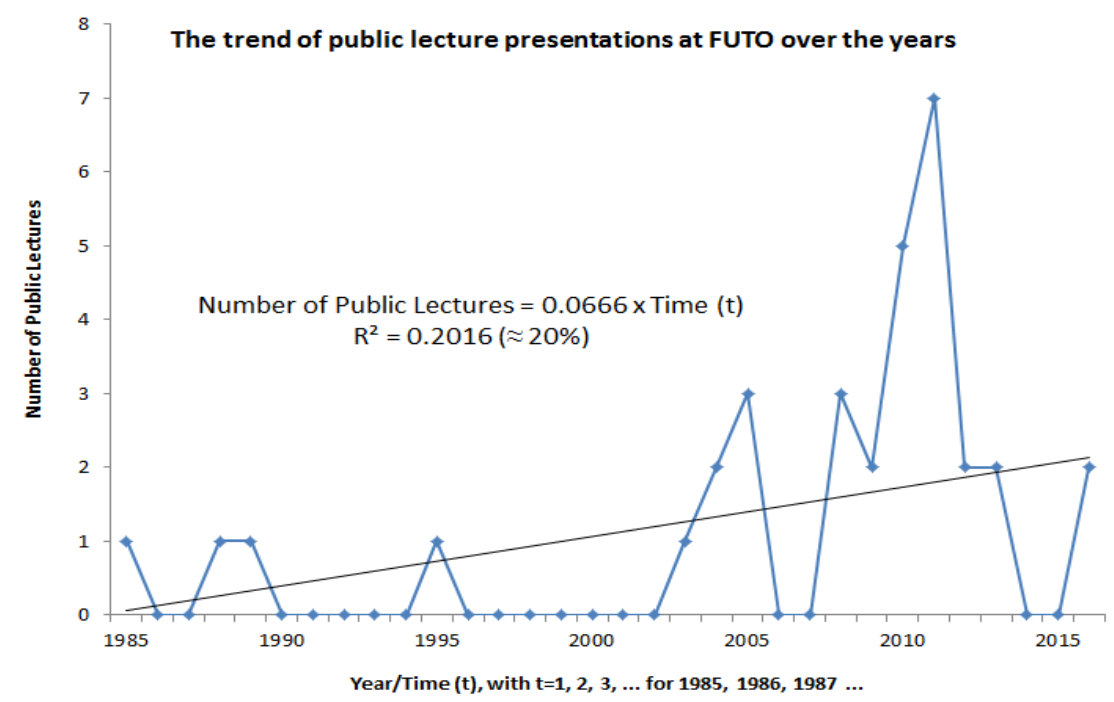

Figure 6: Trends in Public Lecture Presentations in FUTO

Similarly, the public lecture presentations at FUTO have also witnessed an upward trend over the years as shown in the graph. The upward linear trend associated with the public lectures is obtained as:

Number of Public Lectures $=0.0666 \mathrm{x}$ Time $(\mathrm{t})$

Where Year/Time $(t)=1,2,3, \ldots$ correspond to year 1985, 1986, 1987, etc. The R-square value of 0.2016 or $20 \%$ shows that the linear trend in (2) explains only about $20 \%$ of the variations in the public lecture presentations in FUTO. Hence, the estimated linear trend is not suitable for prediction purposes since it does not explain up to $75 \%$ of the variations in the public lecture presentations in FUTO over the years. Hence, it is apparent that it is difficult to project the number of inaugural lectures the university could boast of in the next twenty years. This is also prevalent in the public lectures outing since no trend has also been ascertained. This is a worrisome situation in view of the scholarly and societal importance of both lectures. It could be that the University has not prioritized lectures as important responsibility that every Professor must fulfill.

\section{Conclusion}

Every University pride itself high on its inaugural and public lectures, as a way of giving back to the society what they had labored to produce using public fund. Federal University of Technology, Owerri, which has a total of one hundred and seventy-five Professors at the last count in January 2020, had produced thirty-five inaugural lectures by the year 2019 of which only three of them were female. In spite of the low number of public and inaugural lectures output from the University, there has not been any observed trend with respect to discipline or number, a situation that boxes to a corner the projection of future number of lectures. It is apparent that the University has not prioritized lecture presentation; hence, there may not be any policy in place to determine the trend of presentations. Based on this finding, there is need for the University to consider developing policy as well as motivational packages to ensure that over one hundred and forty Professors who are yet to present their inaugural lectures are quickened to do so. The University community should also be educated by experts through public lectures on trend in our society. Discussion sessions could be initiated to allay the fears and naivety that hinder Professors from presenting their inaugural lectures. 


\section{References}

Ayeni, R. O. (2012). The quest for development: why mathematics matters. $9^{\text {th }}$ Inaugural Lecture Series of Ladoke Akintola University of Technology, Ogbomosho, Oyo State, Nigeria.

Ekpo, C. (2015). Don't shy away from presenting inaugural lectures. The Guardian. Available at: https://guardian.ng/features/education/dont-shy-away-from-presenting-inaugural-lectures/ (Accessed 24 September, 2019).

Evans, L. (2017). University professor as academic leaders: professional leadership development needs and provision. Educational management Administration and Leadership,45(1), 120 - 140. Available at: journals.sagepub.com/doi/pdf/10.1177/1741143215578449 (Accessed 30 December, 2019).

Farinu, G. O. (2015). We are what we eat. $14^{\text {th }}$ Inaugural Lecture Series of Ladoke Akintola University of Technology, Ogbomosho, Oyo State, Nigeria. Available at: https://www.lautech.edu.ng/inaugural/downloads/WE\%20ARE\%20WHAT\%20WE\%20EAT.pdf (Accessed 14January, 2020).

Federal University of Technology, Owerri (FUTO) (2020). List of Professors in FUTO. Senate Meeting Proceedings, March, 2020.

Ivanova, E. \& Ivanova, G. (2018). Public lectures on the novel of G.Gazdanov "An evening with Claire". The European Proceedings of Social and Behavioural Sciences $1798-1808$. Available at: http://doi.org/10.15405/epsbs.2018.12.02.191 (Accessed 8 January, 2020).

Leather, S. (2013). Don't forget the roundabouts: ordeal by inaugural. Available at: simonleather.wordpress.com/tag/inaugural-lecture/ (Accessed 8 January, 2020).

Merriam-Webster Dictionary (n.d). "Professor". Available at: https://www.merriamwebster.com/dictionary/professor. (Accessed 6 January, 2020).

Omolehin, J. O. (2018). Mathematical fixation algoarithm for corruption. $2^{\text {nd }}$ Inaugural Lecture of the Federal University, Lokoja. Available at: https://www.fulokoja.edu.ng/media/docs/37400.pdf (Accessed 8 January, 2020).

Soneye, A. S. O. (2017). Geo-spatial techniques: the bridge to contemporary multi-disciplinary researches and development. An inaugural Lecture delivered at University of Lagos. Available at: file:///C:/Users/FUTOLIB-

ICT/Downloads/Geospatial\%20techniques\%20the\%20bridge\%20to\%20contemporary\%20multi\%20dis ciplinary\%20researches\%20and\%20development\%20(1).pdf(Accessed 8 January, 2020) 